\title{
Segregación residencial en la ciudad latinoamericana
}

\begin{abstract}
In spite of the growing relevance of the socioeconomic residential segregation (SRS) in academic debates and public agendas in Latin American and the Caribbean, the evidence regarding its intensity and magnitude, its tendencies, its reproductive mechanisms and consequences, is fragmentary and weak. Moreover there is little work on comparative indicators of socioeconomic residential segregation between countries (or even in a diachronic way for each country). In this regard, this document offers some pieces of empiric evidence about this social phenomenon, focused in Latin America cities. It aims to contribute in four directions: (a) to advance in the measurement of the SRS in the countries of the region; (b) to study its determinants, especially the intra-metropolitan migration patterns; (c) to explore disparities in behavior and life conditions between rich and poor areas, as first step for the study of the consequences of the SRS; (d) to revise and to analyze policy options considering the international experience
\end{abstract}

Keywords: segregation, urban development, urban poverty, housing policies.

\section{Resumen}

Pese a la emergente presencia de la segregación residencial socioeconómica (SRS) en los debates académicos y en las agendas públicas, la evidencia en América Latina y el Caribe sobre su magnitud e intensidad, sus tendencias, sus mecanismos de reproducción y sus consecuencias es escasa, fragmentaria y poco comparable entre países (e incluso en términos diacrónicos para cada país). Al respecto, este trabajo procura ofrecer alguna evidencia empírica sobre la SRS con especial refer encia a la situación de América Latina y el Caribe, buscando aportar en cuatro sentidos: (a) avanzar en la medición de la SRS en los países de la región; (b) profundizar en el examen de sus determinantes directos, en particular en los patrones de migración intrametropolitana; (c) reflexionar sobre las disparidades de compor tamiento y condiciones de vida entre zonas ricas y pobres, como primer antecedente para el examen de las consecuencias de la SRS; (d) revisar opciones de política relativas a la SRS a nivel internacional.

Palabras clave: segregación, desarrollo urbano, pobreza urbana, políticas habitacionales. 


\section{Introducción. ¿Qué es la segregación residencial?}

L a segregación residencial remite a formas de desigual distribución de grupos fiestan de diferentes maneras, como: (a) la proximidad física entre los espacios residenciales de los diferentes grupos sociales (White, 1983); (b) la homogeneidad social de las distintas subdivisiones territoriales en que se puede estructurar una ciudad (Sabatini, 1999); y (c) la concentración de grupos sociales en zonas específicas de una ciudad (Sabatini, Cáceres y Cerda, 2001; Rodríguez, 2001; Jargowsky, 1996; Massey, White y Phua, 1996). De hecho, definiciones recientes combinan algunas de estas manifestaciones: "La segregación residencial puede definirse, en términos generales, como el grado de proximidad espacial o de aglomeración territorial de las familias pertenecientes a un mismo gr upo social, sea que éste se defina en términos étnicos, etarios, de preferencias religiosas o socioeconómicos, entre otras posibilidades (Sabatini, Cáceres y Cerda, 2001: 27, destacado en el original).

La segregación residencial parece inherente a la vida urbana, pero en la actualidad pareciera tener mayor visibilidad. La principal razón por la cual la segregación residencial está en el tapete es por las adversidades que se le imputan cuando su raíz es socioeconómica, es decir, cuando se trata de segregación residencial socioeconómica (SRS). A grandes rasgos, la SRS actúa como mecanismo de reproducción de las desigualdades socioeconómicas, de las cuales ella misma es una manifestación. Se ha subrayado el hecho de que "aísla a los pobres" (Kaztman, 2001; Dur eau et al., 2002), quienes, al tener como contexto cotidiano sólo pobreza y pares pobres, estrechan sus horizontes de posibilida-

\footnotetext{
Asistente de investigación CELADE. E-mail: jrodriguez@eclac.cl

** Consultor de CEPAL, Docente de Postítulos Internacionales de CEPAL y del Instituto de la Vivienda de la Universidad de Chile, Jefe del Departamento de Estudios MINVU. E-mail: carriagada@minvu.cl

${ }^{* *}$ Una versión ampliada de este artículo fue publicado en CELADE, Naciones Unidas, Serie Población y Desarrollo.
}

des, sus contactos y sus probabilidades de exposición a ciertos códigos, mensajes y conductas funcionales a una movilidad social ascendente. La separación que introduce la SRS se agrava, además, por la reducción de los ámbitos de interacción de los diferentes grupos socioeconómicos, siendo el caso de la segmentación educativa uno de los más sobresalientes y relev antes (CEPAL, 2001); así, se debilitan los contrapesos a la brecha física entre grupos socioeconómicos. Se suman indicios de que la SRS deteriora la vida comunitaria y la capacidad de acción colectiva, asociándose con la violencia y la desconfianza (Tironi, 2003; Rodríguez, 2002 y 2001; CEPAL/CELADE, 2002; CEPAL/ HABITAT, 2001; Kaztman \& Wormald, 2002; Kaztman 2001 y 1999; Sperberg \& Happe, 2000; Castells, 1997; Wilson, 1987).

Pese a la emergente presencia de la SRS en los debates, la evidencia en América Latina y el Caribe es escasa, fragmentaria y poco comparable entre países. Esto repercute en la debilidad o ausencia de intervenciones públicas explícitas sobre este asunto. Precisamente, este trabajo procura ofrecer alguna evidencia empírica sobre la SRS con especial énfasis en la situación de América Latina y el Caribe, buscando aportar en cuatro líneas: (a) avanzar en la medición de la SRS en los países de la región; (b) profundizar en el examen de sus determinantes directos, en particular en los patrones de migración intrametropolitana; (c) indagar en las disparidades de comportamiento y condiciones de vida entre zonas ricas y pobres, como primer antecedente para el examen de las consecuencias de la SRS; (d) revisar opciones de política relativas a la SRS y sus resultados. Cabe anotar que este esfuerzo tiene una doble convicción. Por una parte está el convencimiento de que se necesita más evidencia para comprender la SRS, y que la explotación de los censos de población y vivienda permitiría subsanar esta insuficiencia. Por otra parte, está la cer teza de que la vigencia de la SRS en tanto problema no depende de su tendencias cuantitativas, sino de sus fundamentos, de sus consecuencias para las personas y las comunidades, de sus contrapesos institucionales y de los dispositivos de políticas disponibles para actuar sobre ella o sus secuelas. 


\section{Aproximación empírica a la SRS en América Latina y el Caribe}

No hay estudios sistemáticos sobre la magnitud de la SRS en América Latina y el Caribe. Por lo mismo, los debates sobre sus tendencias suelen apoyarse -si acaso- en experiencias específicas y, con frecuencia, en el uso de medidas diferentes. Como se sostuvo, no ocurre lo mismo en otras latitudes, donde hay indagaciones de largo plazo sobre la evolución de la SRS. Pero en general, en estos últimos casos se trata de segregación residencial racial (SRR), que no es la de interés en el contexto de este trabajo. El hecho de que sea SRR facilita notoriamente su medición, pues se trata de una variable sencilla de identificar y sobre cuyas categorías cabe poca discusión. Normalmente es simple diferenciar entre una mayoría y una minoría racial, y la noción de segregación residencial se vincula directamente a la similitud que hay entre la representación metropolitana de la minoría y su representación en las diferentes subdivisiones del área metropolitana. De esta manera, la aplicación de índices como el de disimilitud de Duncan (D) resulta natural y directa (www.censusscope.org/us/m $1600 /$ chart_dissimilarity.html y http:// mimh200.mimh.edu/PieDb/04476.pdf).

En el caso de la SRS la situación es diferente, por cuanto la línea divisoria no es evidente (¿cuáles son los gr upos socioeconómicos y cómo se identifican?). Así las cosas, un primer paso para aplicar las medidas tradicionales de segregación residencial basadas en el cotejo de la proporción metropolitana de los grupos y de su representación en las diferentes subdivisiones metropolitanas es diferenciar grupos socioeconómicos. Esto fue hecho para el Área Metropolitana del Gran Santiago (AMGS) en una investigación reciente (Rodríguez, 2001). Se consideraron tres variables de segmentación socioeconómica: (a) las necesidades básicas insatisfechas; (b) el hacinamiento; (c) la educación del jefe de hogar. Con estas tres variables se formaron grupos dicotómicos que reflejaban situaciones socioeconómicas polares. Se tuvo, así, el porcentaje de uno y otro grupo para el conjunto del aglomerado metropolitano de Santiago (compuesto por 34 comunas) y su porcentaje para diferentes niveles de subdivisión del aglomerado metropolitano. El cuadro 1 presenta cua- tro niveles distintos, llegando incluso al de las manzanas (algo más de 33 mil en AMGS). Como era de esperar, a medida que se reduce la escala aumenta el valor del índice. La interpretación de los resultados es directa. Por ejemplo, en 1992 había que redistribuir entre las comunas del Gran Santiago a casi el $40 \%$ de los jefes de hogar con estudios universitarios para que en todas ellas este grupo tuviese una representación similar a su peso en el AMGS; la magnitud de la redistribución entre manzanas alcanzaba al 54\% (los valores del cuadro no están expresados en porcentajes).

Una primera pregunta que surge de estos datos es si se trata de niveles elevados o no de D. Aunque todavía no es posible dar una respuesta con fundamentos comparativos rigurosos, un elemento de referencia lo constituyen los D que capturan la magnitud de la SRR en las áreas metropolitanas de Estados Unidos: en el decenio de 1960 este índice alcanzó sus mayores niveles, con valores del orden de $80 \%$ (sin ponderar por el peso de la población afroamericana); en la actualidad supera levemente el $60 \%$, y los especialistas sostienen que "en general, se considera que medidas de disimilaridad sobre 0,6 representan hipersegregación" (http://mimh200.mimh.edu/ PieDb/04476.pdf). Es decir, el patrón de localización de los jefes de hogar con alta educación es segregado en Santiago, pero no alcanza los niveles de separación residencial que hay entre blancos y negros en las áreas metropolitanas de Estados Unidos.

Un hallazgo interesante de la investigación antes citada derivó del análisis diacrónico que se efectuó en el caso del AMGS con los censos consecutiv os de 1982 y 1992. Los resultados (cuadro 1 y cuadro 2) sugieren, contra la idea predominante en la literatura especializada, que la tendencia de la SRS no fue al alza durante el decenio de 1980. En efecto, para los cuatro niveles de desagregación territorial examinados (comunas, distritos y zonas censales y manzanas), el monto de redistribución de jefes de hogar con educación superior que debería efectuarse para que su representación metropolitana estuviese proporcionalmente distribuida entre las subdivisiones era mayor en 1982 que en 1992. Por cierto, estas cifras no son concluyentes, por cuanto es evidente que 
los valores del índice de Duncan dependen críticamente de los criterios usados para diferenciar grupos socioeducacionales dicotómicos.

Ahora bien, datos distintos que se basan en el índice de Duncan entre pobres y no pobres (diferenciados por procedimiento de la línea de la po- breza) muestran, en cambio, que la SRS aumentó en el Gran Santiago entre 1992 y 1998 (Arriagada $\&$ Simioni, 2001). La revisión de índices de "segregación absoluta" muestra que dicha tendencia fue favorecida por el incremento de la sobrerrepr esentación de pobres o probabilidad de pobreza propia de comunas periféricas.

Cuadro 1. Santiago de Chile: índice de disimilitud de Duncan para tres atributos de diferenciación socioeconómica según cuatro diferentes niveles de desagregación geográfica, 1992.

\begin{tabular}{|l|c|c|c|c|}
\hline & Comunas & Distr itos & Zonas censales & Manzanas \\
\hline $\mathrm{NBI}^{\mathrm{a} /}$ & 0,23 & 0,28 & 0,32 & 0,42 \\
\hline $\mathrm{Hacinamiento}^{\mathrm{b} /}$ & 0,22 & 0,26 & 0,3 & 0,39 \\
\hline Educación jefe hogar ${ }^{\mathrm{c} /}$ & 0,39 & 0,44 & 0,47 & 0,54 \\
\hline
\end{tabular}

a/ Hogares sin NBI vs. hogares con NBI (sobre la operacionalización de la NBI ver Rodríguez, 2001)

b/ Hogares sin hacinamiento vs. hogares con hacinamiento (hogares con 2,5 o más personas por dormitorio $\mathrm{u}$ hogares sin dormitorios).

`' Jefes con alta educación (13 o más años de escolaridad que sugiere educación superior vs. 12 o menos años de escolaridad, que sugiere educación media como máximo).

Fuente: Rodríguez, 2001.

Cuadro 2. Santiago de Chile: índice de disimilitud de Duncan para jefes de hogar de dos grupos educativos polares según cuatro diferentes niveles de desagregación geográfica, 1982.

\begin{tabular}{|l|c|c|c|c|}
\hline & Comunas & Distr itos & Zonas censales & Manzanas \\
\hline Educación jefe hogar ${ }^{l} /$ & 0,46 & 0,49 & 0,52 & 0,6 \\
\hline
\end{tabular}

a/Jefes con alta educación (13 o más años de escolaridad, que sugier e educación superior, vs. 12 o menos años de escolaridad, que sugiere educación media como máximo).

Fuente: Rodríguez, 2001.

La combinación de variables de educación con variables de inserción laboral puede resultar una buena opción para la identificación de grupos socioeconómicos polares estrechamente asociados con la variable ingresos. Un ejercicio en tal sentido fue aplicado haciendo uso de las bases de microdatos censales de Chile, 1992 (AMGS); México, 2000 (Zona Metropolitana de la Ciudad de México -muestra expandida) y Perú, 1993 (Área Metropolitana de Lima). En el cuadro 3 se muestran varios indicadores relevantes de la segregación residencial (más bien localización distintiva, en este caso) que registran personas que tienen altas probabilidades de pertenecer a las elites socioproductivas de estos tres países, por tratarse de empleadores con alto nivel educativo.

En primer lugar, en las tres ciudades es claro un patrón de alta concentración territorial de este grupo socioeconómico. En el caso de Santiago el más compacto de los tres-, el sector oriente concentraba una fracción muy significativa de la elite, pues más de la mitad de los patrones con alta educación residía en las 5 comunas más pudientes de la ciudad, que se localizan en dicha zona (las cuales, al ser sumadas, concentraban sólo un 13\% de la PEA metropolitana). En Lima, la concentración se verifica sobre una franja relativamente central que va desde un distrito con costa (Miraflores) hasta uno bastante más al oriente (La Molina); en los 5 municipios más pudientes de dicha franja se localizaba un $10 \%$ de la PEA y se concentraba un $46 \%$ de la elite. Finalmente, en Ciudad de México un 35\% de los patrones con alta educación reside en cuatro delegaciones vecinas del centro-sur del Distrito Federal y en un municipio conurbado del Estado de México aledaño a ellas; estas 5 subdivisiones suman sólo el 11\% de la PEA del área metropolitana. En general, las subdivisiones territoriales en que vive la elite son vecinas, lo que también sugiere SRS a gran escala. 
En segundo lugar, el índice de disimilitud de Duncan ratifica esta pauta de localización segregada de la elite, pues marca entre $38 \%$ en Ciudad de México y $49 \%$ en Santiago de Chile.

En tercer lugar, las cifras reiteran que la separación territorial de la elite socioeconómica, aunque marcada, no alcanza los niveles de segmentación territorial entre blancos y negros en Estados Unidos.

Por último, al estimar el índice de Duncan para un segmento de posición socioeconómica claramente subordinada (asalariados con educación básica o menos), los valores son 10\%, 18\% y 23\% para Ciudad de México, Lima y Santiago, respectivamente; es decir, se trata de una SRS mucho menor que también se aprecia gráficamente en los mapas 2a, 2b y 2c, con una localización dispersa por la periferia metropolitana de las subdivisiones con mayor concentración de grupos subordinados.

Habida cuenta de las variables usadas en los cálculos previos para efectuar la clasificación socioeconómica, resulta natural aproximarse a medidas de la SRS más basadas en las nociones de homogeneidad/heterogeneidad territorial que en las previas, cuyo principio es la similitud "media" entre la estructura social metropolitana y la estr uctura social de las diferentes subdivisiones territoriales en que puede descomponerse el área metropolitana. Las ventajas de esta aproximación se vinculan con la capacidad de usar esta aproximación para detectar las zonas segregadas. En efecto, los índices clásicos proporcionan una medida de síntesis del nivel de la SRS para una unidad territorial (típicamente un área metropolitana), pero sugieren muy poco sobre la modalidad de la segregación -por ejemplo, la distinción entre segregación a gran escala y pequeña escala tan subrayada en trabajos recientes (Rodríguez, 2001; Sabatini, Cácer es y Cerda, 2001) - y menos aún sobre las zonas segregadas sobre las cuales cabría intervenir mediante políticas públicas. Es decir, un $\mathrm{D}$ alto no muestra las zonas donde se concentran los pobres, los grupos étnicos subalternos o las minorías religiosas excluidas. En cambio, el examen de la homogeneidad/heterogeneidad so-

Cuadro 3. Ciudad de México (2000), Lima (1993) y Santiago de Chile (1992): indicadores básicos de concentración territorial de un grupo socioeconómico de elite e índice de disimilitud de Duncan según sudvisiones may ores del área metropolitana.

\begin{tabular}{|c|c|c|c|}
\hline & $\begin{array}{l}\text { Lima } \\
(1993)\end{array}$ & $\begin{array}{c}\text { Ciudad de } \\
\text { México }(2000)\end{array}$ & $\begin{array}{c}\text { Santiago } \\
(1992)\end{array}$ \\
\hline $\begin{array}{l}\text { Porcentaje de la PEA que concentran las } 5 \\
\text { subdivisiones mayores }{ }^{\text {a }} \text { más "exclusivas" }=\end{array}$ & $9,9 \%$ & $11 \%$ & $13 \%$ \\
\hline $\begin{array}{l}\text { Porcentaje de empresarios con educación } \\
\text { alta que concentran las } 5 \text { subdivisiones } \\
\text { mayores } \text { s }^{\mathrm{a}} \text { más "exclusivas" } \text { / }\end{array}$ & $45,9 \%$ & $35,4 \%$ & $55 \%$ \\
\hline $\begin{array}{l}\text { Porcentaje de empresarios con educación } \\
\text { alta en la subdivisión mayor }{ }^{-\underline{ }} \text { más } \\
\text { "exclusiva" }\end{array}$ & $\begin{array}{c}7,71 \% \\
\text { (San Isidro) }\end{array}$ & $\begin{array}{c}5.5 \% \\
\text { (Cuajimalpa de Morelos) }\end{array}$ & $\begin{array}{c}10,34 \% \\
\text { (Vitacura) }\end{array}$ \\
\hline $\begin{array}{l}\text { Indice de Duncan entre subdivisiones } \\
\text { mayores }^{\text {al }}\end{array}$ & $44 \%$ & $38 \%$ & $49 \%$ \\
\hline
\end{tabular}

a/ Las subdivisiones mayor es corresponden a distritos en Lima, delegaciones y municipios en Ciudad de México y comunas en Santiago.

b/Las subdivisiones exclusivas corresponden a las que registran una mayor propor ción de empresarios con alta educación dentro de su PEA residente. En Ciudad de México, donde el 1,2\% de la PEA es patrón con alto nivel educativo, corresponden a Cuajimalpa de Mor elos (5,7\%); Huixquilucán (5,3\%); Miguel Hidalgo (3,8\%); Benito Juárez (3,7\%) y Coyoacán (2,7\%). En Lima, donde el 1,1\% de la PEA es patrón con alto nivel educativo, corresponden a San Isidro (7,7\%); La Molina (6,6\%); Miraflores (4,8\%); S an Borja (4,4\%) y Santiago de Surco (4,3\%). En $S$ antiago, donde el 1,7\% de la PEA es patrón con alto nivel educativo, corresponden a Vitacura (10,3\%); Las Condes (7,3\%); Lo Barnechea (6,9\%); Providencia (6,8\%) y La Reina (4,9\%).

Fuente: procesamiento especial de las bases de datos censales con REDATAM (insumos de los cálculos disponibles a solicitud). 
cial de las distintas subdivisiones detecta directamente zonas de alta homogeneidad de grupos subalternos, pues por definición se tiene la media de la variable -y por ende, se sabe si la subdivisión tiene una situación socioeconómica precaria o noe indicadores de dispersión (varianza, desviación estándar y coeficiente de variación) que sugieren el grado de homogeneidad/heterogeneidad. Zonas de bajo nivel socioeconómico y altamente homogéneas serían zonas segregadas, donde la pobr eza tendería a encerrarse y reproducirse (Tironi, 2003; CEPAL/CELADE, 2002; Kaztman, 2003 y 2001; Massey, 2002; CEPAL, 2001).

Ahora bien, un asunto que no debe ser descuidado es el relativo al indicador de dispersión usado para identificar zonas homogéneas. Puede concluirse que el indicador apropiado para comparar niveles de homogeneidad es el coeficiente de variación, pues expresa la magnitud de la desviación estándar en función de la media de la distribución.

En la región, hay evidencia de que existe una escasa mezcla social en los espacios donde reside la elite. Los cuadros $4 \mathrm{a}$ y $4 \mathrm{~b}$ son ilustrativos al respecto, pues la varianza y la desviación estándar de la escolaridad media es mayor en las subdivisiones con mayor escolaridad promedio (lo que, como ya se dijo, no indica heterogeneidad, pues por la fórmula de cálculo de la varianza se debe al mayor promedio de escolaridad en ellas), pero el coeficiente de variación es mucho menor en ellas.

Otra opción para medir SRS es usar la dispersión de la variable socioeconómica que se considere relevante (años de educación, número de NBI, ingresos, etc.) y obtener su varianza para el conjunto del área metropolitana (varianza de la variable medida a escala de individuo u hogares residentes en el área metropolitana). Luego, descomponer dicha varianza entre varianza entre subdivisiones y varianza dentro de las subdivisiones. La medida de la SRS corresponde al cociente de la varianza entre subdivisiones y la varianza total; como la primera es un subconjunto de la segunda, el resultado se interpreta como la proporción de la disparidad socioeconómica total que se debe a localización territorial diferencial de los estratos socioeconómicos.

Cuadro 4a. Ciudad de México (2000), Santiago (1992), São Paulo (2000) y Río de Janeiro (2000): tres subdivisiones territoriales de mayor promedio de escolaridad (personas de entre 25 y 40 años) según población, media de escolaridad y tres índices de dispersión de escolaridad.

\begin{tabular}{|c|c|c|c|c|c|}
\hline $\begin{array}{l}\text { Área metropolitana, año } \\
\text { y nombre de la subdivisión } \\
\text { territorial }\end{array}$ & $\begin{array}{l}\text { Población de } \\
25 \text { a } 39 \text { años }\end{array}$ & $\begin{array}{c}\text { Media de } \\
\text { años de } \\
\text { estudio 25-39 } \\
\end{array}$ & Varianza & $\begin{array}{l}\text { Desviación } \\
\text { estándar }\end{array}$ & $\begin{array}{l}\text { Coeficiente } \\
\text { de variación }\end{array}$ \\
\hline \multicolumn{6}{|c|}{ Zona Metropolitana de la Ciudad de México (2000) } \\
\hline Benito Juárez (delegación) & 95.390 & 13,2 & 13,9 & 3,7 & 28,3 \\
\hline Coyoacán (delegación) & 169.766 & 11,7 & 17 & 4,1 & 35,1 \\
\hline Miguel Hidalgo (delegación) & 89.097 & 11,4 & 16 & 4 & 35,2 \\
\hline \multicolumn{6}{|c|}{ Area Metropolitana del Gran Santiago (1992) } \\
\hline Vaticano (distrito censal) & 3.752 & 14,3 & 14,1 & 3,8 & 26,2 \\
\hline $\begin{array}{l}\text { Príncipe de Gales } \\
\text { (distrito censal) }\end{array}$ & 3.497 & 14,3 & 13,9 & 3,7 & 26,1 \\
\hline $\begin{array}{l}\text { Sebastián Elcano } \\
\text { (distrito censal) }\end{array}$ & 2.922 & 14,3 & 14,7 & 3,8 & 26,8 \\
\hline \multicolumn{6}{|c|}{ Área Metropolitana del Gran São Paulo (2000) } \\
\hline Moema (distrito censal) & 17.797 & 13,9 & 14,3 & 3,8 & 27,1 \\
\hline $\begin{array}{l}\text { Jardim Paulista } \\
\text { (distrito censal) }\end{array}$ & 20.048 & 13,7 & 17,8 & 4,2 & 30,5 \\
\hline Vila Mariana (distrito censal) & 29.993 & 13,4 & 17,8 & 4,2 & 31,5 \\
\hline \multicolumn{6}{|c|}{ Área Metropolitana del Gran Río de Janeiro (2000) } \\
\hline Niteroi (distrito censal) & 92.601 & 10,6 & 21,1 & 4,6 & 43,3 \\
\hline Itaipú (distrito censal) & 13.794 & 10 & 24 & 4,9 & 48,9 \\
\hline $\begin{array}{l}\text { Río de Janeiro } \\
\text { (distrito censal) }\end{array}$ & 1.371 .216 & 9,3 & 18,6 & 4,3 & 46,5 \\
\hline
\end{tabular}

Fuente: procesamiento especial de las bases de datos censales con REDATAM (insumos de los cálculos disponibles a solicitud). Excluye a la población que no contestó las preguntas necesarias para calcular años de escolaridad. 
Cuadro 4b. Ciudad de México (2000), Santiago (1992), São Paulo (2000) y Río de Janeiro (2000): tres subdivisiones territoriales de MENOR promedio de escolaridad (personas de entre 25 y 40 años) según población, media de escolaridad y tres índices de dispersión de escolaridad.

\begin{tabular}{|c|c|c|c|c|c|}
\hline $\begin{array}{l}\text { Área metropo litana, año } \\
\text { y nombre de la subdivisión } \\
\text { territorial }\end{array}$ & $\begin{array}{l}\text { Población de } \\
25 \text { a } 39 \text { años }\end{array}$ & $\begin{array}{c}\text { Media de } \\
\text { años de } \\
\text { estudio 25-39 }\end{array}$ & Varianza & $\begin{array}{l}\text { Desviación } \\
\text { estándar }\end{array}$ & $\begin{array}{l}\text { Coeficiente } \\
\text { de variación }\end{array}$ \\
\hline \multicolumn{6}{|c|}{ Zona Metropolitana de la Ciudad De México (2000) } \\
\hline Tizayuca (municipio) & 1.314 & 7,9 & 12,2 & 3,5 & 44,3 \\
\hline Chimalhuacan (municipio) & 120.512 & 7,4 & 11,1 & 3,3 & 45,3 \\
\hline $\begin{array}{l}\text { Valle de Chalco } \\
\text { Solidaridad (municipio) }\end{array}$ & 73.760 & 7,3 & 11,3 & 3,4 & 46,2 \\
\hline \multicolumn{6}{|c|}{ Área Metropolitana del G ran Santiago (1992) } \\
\hline $\begin{array}{l}\text { San Gregorio Oriente } \\
\text { (distrito censal) }\end{array}$ & 4.253 & 8 & 11,2 & 3,4 & 41,7 \\
\hline La Platina (distrito censal) & 15.887 & 7,8 & 9,9 & 3,2 & 40,4 \\
\hline Cerro Negro (distrito censal) & 3.754 & 7,3 & 10,1 & 3,2 & 43,8 \\
\hline \multicolumn{6}{|c|}{ Área Metropolitana del G ran Sao Paulo (2000) } \\
\hline $\begin{array}{l}\text { Boa Vista Paulista } \\
\text { (distrito censal) }\end{array}$ & 16.694 & 6 & 11,9 & 3,5 & 57,2 \\
\hline $\begin{array}{l}\begin{array}{l}\text { Francisco Morato } \\
\text { (distrito censal) }\end{array} \\
\end{array}$ & 31.104 & 5,7 & 11,9 & 3,4 & 59,6 \\
\hline Juquitiba (distrito censal) & 6.084 & 5,7 & 12,6 & 3,6 & 62,4 \\
\hline \multicolumn{6}{|c|}{ Area Metropolitana del Gran Río de Janeiro (2000) } \\
\hline $\begin{array}{l}\text { Pedro do Rio (distrito censal) } \\
\text { Pito }\end{array}$ & 3.157 & 5.5 & 11.1 & 3.3 & 60.4 \\
\hline Posse (distrito censal) & 2.263 & 5.5 & 10.7 & 3.3 & 59.8 \\
\hline $\begin{array}{l}\text { São José do Vale } \\
\text { do Río Preto (distrito censal) }\end{array}$ & 4.741 & 4.8 & 13.5 & 3.7 & 73.9 \\
\hline
\end{tabular}

Fuente: procesamiento especial de las bases de datos censales con REDATAM (insumos de los cálculos disponibles a solicitud). Excluye a la población que no contestó las preguntas necesarias para calcular la estimación.

El cambio de esta varianza, al ir bajando el nivel de agregación geográfica, sugiere si la SRS es de alta o baja escala (ver Rodríguez, 2001).

En el cuadro 5 se exponen los resultados de una aplicación de este procedimiento, usando bases de microdatos censales para varias ciudades de la región. Se usan dos variables. Por una parte están las carencias habitacionales, medida de pobreza, calculando necesidades básicas insatisfechas en ocho dimensiones, habitacionales y de saneamiento. Cada vivienda particular ocupada recibe una puntuación de 0 a 8 según el número de NBI (8 revela unas condiciones de vida muy precarias), y luego con esos valores se calcula la media de NBI por vivienda en cada subdivisión. Por otra parte, están los años de educación, variable clave para la identificación socioeconómica de las personas. En este caso se optó por la escolaridad de los jefes de hogar. Los resultados de esta aplicación muestran que si el indicador socioeconómico fuesen las NBI, en las ciudades analizadas habría una escasa SRS a gran escala, ya que en el caso extremo (Ciudad de Guatemala), un 7\% de la varianza total de la variable número de NBI se explica por varianza entre subdivisiones grandes. Un panorama muy diferente se aprecia a escala de subdivisiones pequeñas, ya que la varianza de naturaleza territorial llega a explicar casi la mitad de la varianza total en algunas ciudades como Panamá. Con todo, aun considerando bajos de desagr egación (manzanas en algunos casos), la varianza intrasubdivisión predomina, lo que sugiere un grado importante de mezcla a tales escalas. Cuando la variable de estratificación social es la escolaridad del jefe de hogar, se advierten niveles más altos de SRS entre subdivisión mayores (segregación a gran escala). En particular en Santiago (1992), un 18\% de la varianza total de esta escolaridad se explicaba por diferencia de escolaridad entre comunas, y el guarismo llegaba a $17 \%$ en el caso de Montevideo. Ahora bien, en las tres ciudades examinadas la varianza de escolaridad entre subdivisiones menores explica menos de un tercio de la varianza total (cuadro 5 y gráfico 1), lo que sugiere que a esta pequeña escala hay mezcla socioeducativa. 
En suma, hay diferentes medidas y procedimientos para mensurar la segr egación residencial en sus difer entes variantes. En el caso de la SRS, las medidas basadas en las similitud entre la proporción global de un grupo y la proporción en las diferentes subdivisiones exige agrupamientos a priori, lo que introduce una cuota de discrecionalidad en la medición. Por cierto, existen criterios relativamente consensuales para clasificar grupos socioeconómicos específicos (la elite, el sector informal marginal, los grupos medios, el sector popular urbano, etc.), por lo que la operación con índices de disimilitud puede considerarse un primer ejercicio a efectuar. Otras opciones son identificar zonas de composición social homogénea que pueden ser segregadas (áreas de pobres) o exclusivas (zonas de la elite). La opción usada en este trabajo es operar con la proporción de la varianza total de la variable de clasificación socioeconómica (car encias habitacionales, años de escolaridad, ingr esos), que se explica por varianza entre subdivisiones; al aplicar de forma recursiva este procedimiento, pero bajando de manera sistemática el nivel geográfico de la subdivisión, es posible tener una aproximación de la escala de la SRS. Finalmente, una alternativa no explorada en este trabajo, pero cuyo uso está previsto para indagaciones futuras, son medidas de detección de agrupamientos territoriales desarrolladas por la econometría espacial, tales como el índice de Moran en sus expresiones global y local (San-II Lee,
2001; Aroca, 2000; Anselin, 1995). Ahora bien, con independencia de la variedad de las medidas usadas y por usar, la conclusión es que sí es posible aquilatar la SRS usando la información que proporcionan los censos de población y vivienda.

\section{Los determinantes directos de la SRS: el caso de la migración intrametropolitana}

La SRS es, en última instancia, un asunto de distribución de la población en el territorio metropolitano, por lo cual una parte significativa de sus determinantes se halla en el campo demográfico. En términos generales, tres son las principales fuentes de determinación y cambio de la SRS: (a) los diferenciales de crecimiento natural de los diferentes grupos socioeconómicos, que contribuyen a determinar la forma como tales grupos se distribuyen en el espacio urbano, y por lo tanto, afectan la intensidad y las formas de la SRS; (b) los patrones de migración intra y extrametropolitana, pues si la gente migra hacia zonas en las que hay alta concentración de pares (en términos socioeconómicos) cabe esperar una SRS creciente; en cambio, si la migración se efectúa para salir de tales zonas y trasladarse a otras donde predominan grupos socioeconómicos diferentes, cabe esperar una atenuación de la SRS; (c) modificaciones dentro de cada gr upo social ${ }^{1}$, pues si la po-

Cuadro 5. América Latina y el Caribe: índice de SRS basado en la varianza entre subdivisiones territoriales de las condiciones de vida (NBI) y de la escolaridad del jefe de hogar, según diferentes niveles de jerarquía geográfica.

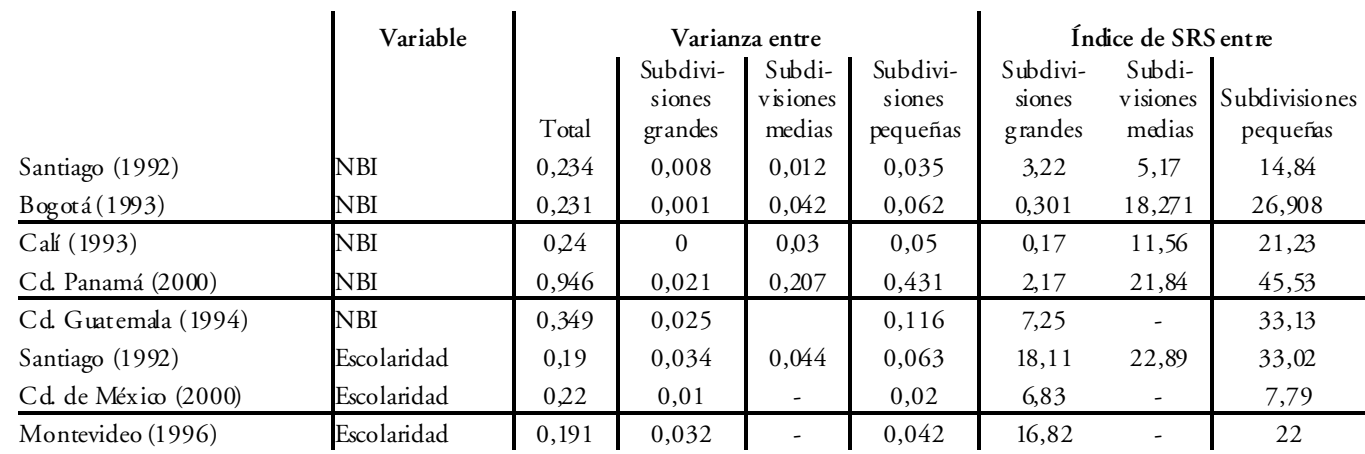

Fuente: Rodríguez (2001) para Santiago de Chile, y procesamientos especiales de las bases de microdatos censales para los otros países.

${ }^{1}$ Esta fuente no se aplica para todos los tipos de segregación, por cuanto hay gr upos cuyos rasgos distintivos son irreversibles en el corto plazo (p.ej. la raza). 
blación de determinadas zonas de la ciudad modifica sus condiciones socioeconómicas, la intensidad y la forma de la SRS varía.

Descomponer la tendencia de la segregación en estas tres fuentes para examinar cómo opera cada una y cuánto pesan en su evolución final es una tarea que aún no parece haberse emprendido en la región. Además de los esfuerzos de formalización y cálculo que supone dicha tarea, hay serias dificultades para obtener la información necesaria. En esta sección se ofrecen antecedentes sobre la migración intrametropolitana, y se efectúa un análisis de su papel en las tendencias de la SRS. Se trata de una información novedosa, no obstante ser recogida por los censos nacionales de población. Las dificultades para manejar grandes bases de datos conspiraban contra la construcción de matrices de migración intrametropolitanas según características socioeconómicas. Hoy es factible hacerlo. Con todo, interesa sobremanera mostrar unos resultados que proporcionen una aproximación operativa a un tema sobre el cual hay interés pero muy poca evidencia empírica en la región; es claro que tal aproximación sugiere una línea de investigación de gran valor para el estudio de los asuntos urbanos.
El procesamiento de los microdatos censales de cuatro aglomerados metropolitanos de América Latina permite un conjunto de inferencias relevantes tanto para el tema de la movilidad intrametropolitana como para el examen de la SRS. Antes de presentar una síntesis de los resultados (cuyos cálculos de base -en particular las matrices derivadas de migración- están disponibles según solicitud), cabe subrayar que la migración que se examinará será migración reciente entre comunas (ha ocurrido dentro de los 5 años previos al censo, y es entre comunas por que deriva de la consulta sobre comuna o municipio de residencia 5 años antes del censo). Es la forma más idónea de medir migración relativamente vigente, $y$ por la forma como capta la información permite la estimación de tasas de migración, y no sólo de proporciones migratorias (Welti, 1998 y 1997; Villa, 1991). Por cierto tiene limitaciones. Por una parte, pierde movimientos dentro de las comunas/municipios, e incluso respecto de los que capta no puede precisar su origen a un nivel inferior al municipal. Por otra parte, pierde movimientos intermedios dentro del período de referencia.

Cabe tener presente que la mayor parte de los cálculos no están orientados a cuantificar el volu-

Gráfico 1. Índices de SRS basado en la varianza de la escolaridad media del jefe de hogar entre subdivisiones territoriales grandes (comunas) y pequeñas (manzanas o localidades): áreas metropolitanas del Gran Santiago, Bogotá, Ciudad de México y Montevideo.

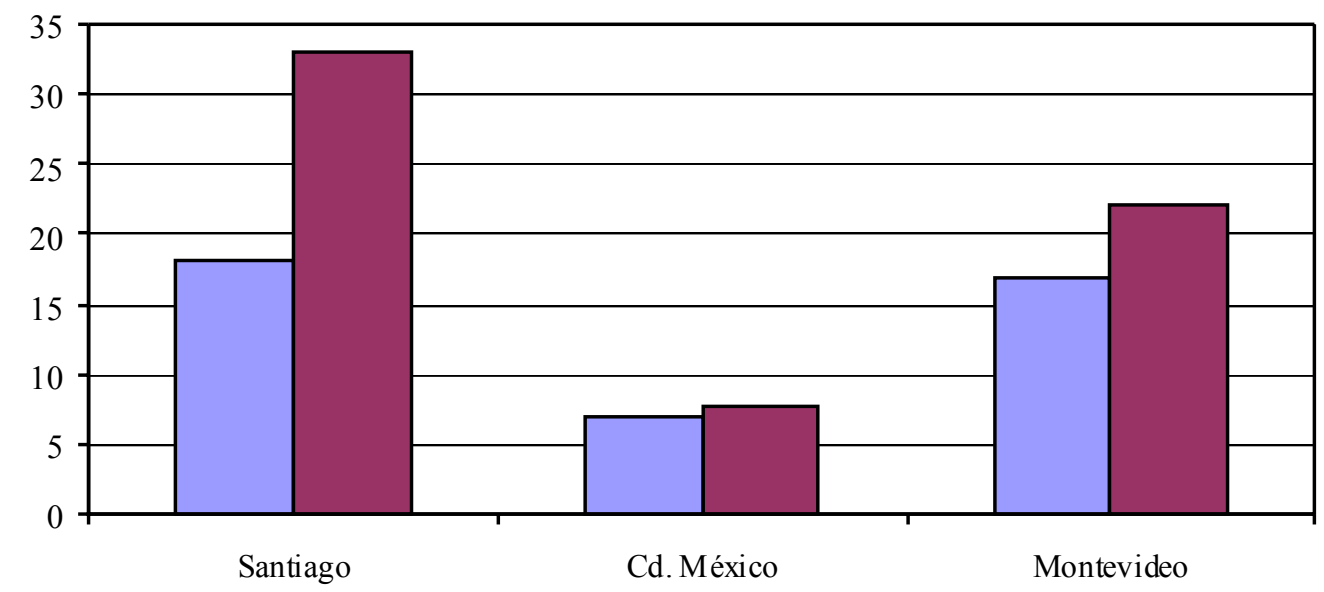

Grandes Areas Areas Menores 
men total de la migración intrametropolitana, sino a examinar su efecto sobre la SRS. La estrategia seguida es indagar en la selectividad socioeconómica de los flujos entre comunas/municipios componentes de los aglomerados metropolitanos, procurando verificar si tal selectividad existe y si tiende a incrementar o a reducir la SRS. Dado que la variable educativa es la que ha sido utilizada para la cuantificación de la SRS, en este caso también se recurrirá a ella. Por lo mismo, resulta necesario controlar factores extrínsecos, en particular la edad; esto último se hizo considerando sólo a las personas de entre 25 y 39 años.

Una última advertencia dice relación con las comparaciones entre las ciudades, las que no son del todo procedentes. El factor que actúa como barr era más relevante para los cotejos es que mientras en Santiago y Ciudad de México ninguna comuna o municipio (delegación) alberga más de un $10 \%$ de la población, en São Paulo y Río de Janeiro los municipios homónimos contienen más del $50 \%$ de la misma. Esto repercute, por ejemplo, en las magnitudes de la migración intrametropolitana, pues muchos movimientos no son captados por los censos brasileños; asimismo, hace que los desplazamientos residenciales intrametropolitanos que captura el censo tengan un marcado carácter centroperiferia o periferia-periferia, pues los movimientos dentro del "ámbito central" (municipios de São Paulo y Río de Janeiro), no son captados. También inhibe las comparaciones entre ciudades el hecho de que en Santiago hubo una modificación de lí- mites municipales en el período de referencia, lo que parece haber inducido una declaración exagerada del cambio de residencia entre comunas. Dado que no hay antecedentes para suponer que esta exageración tenga algún sesgo socioeconómico, las cifras promedio que presentan son válidas, lo que no es tan claro en el caso de las magnitudes de la migración.

En el cuadro 6 se proporcionan algunos indicadores seleccionados que permiten poner en perspectiva la relación entre migración intrametropolitana y segregación. En términos de cuantía, las cifras revelan una cantidad significativa de cambios de residencia en el período de referencia, por lo que hay un peso cuantitativo de base para incidir en el patrón de segregación. Como se había anticipado, los niveles de movilidad intrametropolitana son mucho menores en Brasil, en gran medida por el "ocultamiento" de movimientos que resulta del gran tamaño de sus municipios centrales. En términos de los rasgos de los migrantes, destaca el hecho de que los migrantes intrametropolitanos tienen un nivel de escolaridad superior a los nativos; nuevamente las ciudades brasileñas se distinguen a este respecto, lo que está ligado a la condición centro-periferia o periferia-periferia que tienen los movimientos intrametropolitanos capturados por el censo. Esta selectividad socioeduca-cional "hacia arriba" entre los que se mueven dentro de la ciudad es relevante para efectos de medición, pues una primera lectura basada en la comparación de la escolari-

Cuadro 6. Indicadores seleccionados de la migración intrametropolitana de personas de entre 25 y 39 años en el momento del censo, en cuatro ciudades de la región.

\begin{tabular}{|l|c|c|c|c|}
\hline $\begin{array}{l}\text { Ciudad y período de } \\
\text { referencia de la migración }\end{array}$ & $\begin{array}{c}\text { Cantidad de } \\
\text { migrantes intra- } \\
\text { metropolitanos }\end{array}$ & $\begin{array}{c}\text { Tasa (por mil) } \\
\text { de movilidad } \\
\text { intra- } \\
\text { metropolitana }\end{array}$ & $\begin{array}{c}\text { Escolaridad } \\
\text { media } \\
\text { migrantes } \\
\text { intrame- } \\
\text { tropolitanos }\end{array}$ & $\begin{array}{c}\text { Escolaridad } \\
\text { media no } \\
\text { migrantes }\end{array}$ \\
\hline Ciudad de México (1995-2000) & 552.801 & 24,5 & 10,53 & 9,83 \\
\hline Río de janeiro (1995-2000) & 102.190 & 7,8 & 8,4 & 8,5 \\
\hline Santiago (1987-1992) & 306.940 & 53,1 & 11 & 10,3 \\
\hline Sáo Paulo (1995-2000) & 222.733 & 9,88 & 8,06 & 8,48 \\
\hline
\end{tabular}

Nota: la tasa de movilidad intrametropolitana es media anual; su denominador es la población residente en el aglomerado metropolitano al momento del censo. La escolaridad media corresponde a años de educación (su cálculo excluye a las personas que no respondieron las preguntas necesarias para la estimación).

Fuente: procesamiento especial de las bases de datos censales con REDATAM (insumos de los cálculos disponibles a solicitud). 
dad media de inmigrantes y no migrantes por comuna tiene una alta probabilidad de arrojar un resultado ingenuo de "todas las comunas ganan con la migración", por cuanto los que llegan tienden a tener más educación que los nativos. En tal sentido, se refuerza la necesidad de contar con algoritmos más refinados para evaluar el impacto de esta migración sobre el capital educativo del origen y el destino.

El escrutinio de las matrices de migración ratifica el patrón de intercambio migratorio entre centro y periferia de las ciudades de la región. Tanto en Ciudad de México como en Santiago las subdivisiones que forman el anillo interior registran altos índices de emigración neta, mientras que las subdivisiones periféricas son las que ganan; es decir, parte importante de la expansión periférica se origina por expulsión de las zonas centrales. En São Paulo y Río de Janeiro el intercambio migratorio sigue un patrón estilizado: el municipio central pierde una abultada cantidad de población por migración, la que se distribuye entre los restantes municipios (con algunas excepciones como Niteroi en Río y O sasco, Santo André, y São Caetano do Sul en São Paulo, que también tienen emigración neta). Por cierto, la imagen de periferia que recibe flujos migratorios no significa que la gente esté yéndose a los extramuros de las ciudad. Tal vez Santiago, con la acelerada expansión de Puente Alto y Maipú se acerca a aquello, pero en Ciudad de México son municipios que están entre los centrales y los periféricos-como Ecatepec de Morelos, Tultitlán, Chimalhuacán y Coacalco de Berriozabal-, los que ostentan la may or migración neta positiva.

El examen pormenorizado de los flujos intrametropolitanos excede los límites de este trabajo (aunque las matrices se encuentran disponibles según solicitud); sin embargo, se advierten conexiones estructurales entre municipios cercanos. En el período 1995-2000, casi 54 mil personas entre 25 y 39 años (para el año 2000) se trasladaron desde la delegación de Gustavo Madero (en el nor te del D.F.) a otras delegaciones o muni-

Cuadro 7a. Ciudad de México (2000), Santiago (1992), São Paulo (2000) y Río de Janeiro (2000): Tres subdivisiones territoriales de mayor promedio de escolaridad (personas de entre 25 y 40 años) según media de escolaridad de inmigrantes y emigrantes intrametropolitanos, no migrantes y tres formas de cotejar el efecto de la migración sobre la escolaridad media.

\begin{tabular}{|c|c|c|c|c|c|}
\hline $\begin{array}{c}\text { Área metropolitana, año } \\
\text { y nombre de la subdivisión } \\
\text { territorial }\end{array}$ & $\begin{array}{l}\text { Escolaridad } \\
\text { inmigrantes } \\
\text { intrametropo- } \\
\text { litanos }\end{array}$ & $\begin{array}{c}\text { Escolaridad } \\
\text { emigrantes } \\
\text { intrametropo- } \\
\text { litanos }\end{array}$ & $\begin{array}{c}\text { Escolaridad no } \\
\text { migrantes }\end{array}$ & $\begin{array}{c}\text { Diferencia } \\
\text { escolaridad } \\
\text { inmigrantes y } \\
\text { emigrantes } \\
\text { intrametropo- } \\
\text { litanos }\end{array}$ & $\begin{array}{c}\text { Diferencia } \\
\text { escolaridad } \\
\text { inmigrantes } \\
\text { intrametropo- } \\
\text { litanos y no } \\
\text { migrantes }\end{array}$ \\
\hline \multicolumn{6}{|c|}{ Zona Metropolitana de la Ciudad de México (2000) } \\
\hline Benito Juárez (delegación) & 13,7 & 12,6 & 13,6 & 1,17 & 0,14 \\
\hline Co yoacán (delegación) & 13,1 & 12,2 & 11,5 & 0,95 & 1,61 \\
\hline Miguel Hidalgo (delegación) & 12,2 & 11,9 & 11,2 & 0,27 & 0,98 \\
\hline \multicolumn{6}{|c|}{ Área Metropolitana del Gran Santiago (1992) } \\
\hline Vitacura & 13,8 & 12,9 & 14,0 & 0,88 & $-0,19$ \\
\hline Providencia & 14,0 & 13,6 & 14,0 & 0,45 & 0,04 \\
\hline Las Condes & 13,9 & 12,5 & 13,5 & 1,36 & 0,37 \\
\hline \multicolumn{6}{|c|}{ Area Metropolitana del Gran São Paulo (2000) } \\
\hline São Cayetano de Sul & 11,5 & 10,1 & 11,0 & 1,39 & 0,46 \\
\hline São B ernardo do Campo & 9,8 & 9,9 & 8,8 & $-0,15$ & 0,96 \\
\hline São Paulo & 9,8 & 7,9 & 8,9 & 1,88 & 0,87 \\
\hline \multicolumn{6}{|c|}{ Área Metropolitana del Gran Río de Janeiro (2000) } \\
\hline Niteroi & 11,7 & 9,6 & 10,4 & 2,14 & 1,26 \\
\hline Río de Janeiro & 10,0 & 8,4 & 9,3 & 1,62 & 0,71 \\
\hline Nilópolis & 8,8 & 8,1 & 8,8 & 0,68 & 0,01 \\
\hline
\end{tabular}

Fuente: procesamiento especial de las bases de datos censales con REDATAM (insumos de los cálculos disponibles a solicitud). 
cipios de la ZMCM, una cifra significativa si se considera que la población media de dicho gr upo en el período 1995-2000 fue del orden de 330 mil personas. Un tercio de éstas se dirigió al municipio conurbado de Ecatepec de Morelos, en el nor oriente de la ciudad y casi vecino con Gustavo Madero (el flujo en sentido inverso fue de $3 \mathrm{mil}$ 200 personas de entre 25 y 39 años al momento del censo). En cambio, los emigrantes de delegaciones relativamente centrales y netamente expulsoras de población, pero localizadas en el sur del D.F. (como Coyoacán o Alvaro Obregón) tuvieron destinos mucho más diversificados, ya sea en municipios conurbados del sur-oriente (Ixtapaluca) o del sur-poniente (Huixquilcucán), $\mathrm{u}$ otras delegaciones del sur del D.F. (Tlalpán, Iztapalapa).

Finalmente, en lo que atañe a la relación entre migración y segr egación, la selectividad educativa de los flujos está altamente correlacionada con su destino, lo que sugiere que la migración intrametropolitrana tiende a profundizar la SRS.
Nuevamente, el análisis pormenorizado de los flujos escapa a los límites del documento. Ahora bien, un examen de los resultados por comunas muestra que la mayor parte de las comunas ganan capital educativo con la migración intrametropolitana al comparar inmigrantes con nativos, pero como ya se planteó, tal cotejo no es el relevante para evaluar el impacto de la migración intrametropolitana sobre el capital humano municipal. El indicador más preciso es la diferencia entre la escolaridad de los inmigrantes intrametropolitanos y los emigrantes intrametropolitanos. Y con dicho indicador aumentan las comunas perdedoras netas de recursos humanos. En general, las comunas con mayores índices educativos son las que registran mayores ganancias de capital humano por migración.

Las intercorrelaciones simples entre los indicadores de escolaridad de los inmigrantes, emigrantes y no migrantes son altas. Aquello sugiere dos interpretaciones distintas, aunque igualmente válidas. Primero, que opera un principio

Cuadro 7b. Ciudad de México (2000), Santiago (1992), São Paulo (2000) y Río de Janeiro (2000): Tres subdivisiones territoriales de MENOR promedio de escolaridad (personas de entre 25 y 40 años) según población, media de escolaridad y tres indicadores de dispersión de la distribución de la escolaridad.

\begin{tabular}{|c|c|c|c|c|c|}
\hline $\begin{array}{c}\text { Área metropolitana, año y } \\
\text { nombre de la subdivisión } \\
\text { territorial }\end{array}$ & $\begin{array}{c}\text { Escolaridad } \\
\text { inmigrantes } \\
\text { intrametropo- } \\
\text { litanos }\end{array}$ & $\begin{array}{l}\text { Escolaridad } \\
\text { emigrantes } \\
\text { intrametropo- } \\
\text { litanos }\end{array}$ & $\begin{array}{c}\text { Escolaridad no } \\
\text { migrantes }\end{array}$ & $\begin{array}{c}\text { Diferencia } \\
\text { escolaridad } \\
\text { inmigrantes y } \\
\text { emigrantes } \\
\text { intrametropo- } \\
\text { litanos }\end{array}$ & $\begin{array}{c}\text { Diferencia } \\
\text { escolaridad } \\
\text { inmigrantes } \\
\text { intrametropo- } \\
\text { litanos y no } \\
\text { migrantes }\end{array}$ \\
\hline \multicolumn{6}{|c|}{ Zona Metropolitana de la Ciudad de México (2000) } \\
\hline Tizayuca (municipio) & 7,6 & 9,3 & 8,1 & $-1,76$ & $-0,55$ \\
\hline Chimalhuacan (municipio) & 7,5 & 8 & 7,4 & $-0,47$ & 0,13 \\
\hline \multicolumn{6}{|l|}{ Valle de Chalco Solidaridad } \\
\hline (municipio) & 8,3 & 7,8 & 7,1 & 0,52 & 1,24 \\
\hline \multicolumn{6}{|c|}{ Área Metropolitana del Gran Santiago (1992) } \\
\hline La Pintana & 8,3 & 9,2 & 8,3 & $-0,84$ & 0,01 \\
\hline Cerro Navia & 9,1 & 9,6 & 8,8 & $-0,44$ & 0,33 \\
\hline Huechuraba & 9,1 & 9,2 & 8,8 & $-0,13$ & 027 \\
\hline \multicolumn{6}{|c|}{ Área Metropolitana del Gran São Paulo (2000) } \\
\hline Francisco Morato & 5,9 & 6,9 & 5,8 & $-0,97$ & 0,06 \\
\hline Juquitiba & 5,3 & 7,4 & 5,9 & $-2,61$ & $-0,52$ \\
\hline Itaquaquecetuba & 6,2 & 6,7 & 6,2 & $-0,45$ & 0 \\
\hline \multicolumn{6}{|c|}{ Area Metropolitana del Gran Río de Janeiro (2000) } \\
\hline \multicolumn{6}{|l|}{ São José do Vale do Rio } \\
\hline Preto & 8,8 & 5,4 & 4,9 & 3,32 & 3,82 \\
\hline Itaboraí & 7,4 & 6,6 & 6,1 & 0,74 & 1,30 \\
\hline Japeri & 6,5 & 7,1 & 6,1 & 0,63 & 0,4 \\
\hline
\end{tabular}

Fuente: procesamiento especial de las bases de datos censales con REDATAM (insumos de los cálculos disponibles a solicitud). 
de selectividad socioeconómica de la atracción, pues la educación de los inmigrantes tiende a aumentar con la educación media del lugar de destino. Segundo, que no opera -a gran escala, al menos- un mecanismo de salida (o expulsión) de los "diferentes", ya que el nivel educativo de los emigrantes tiende a aumentar con la educación media del lugar de origen (un correlación negativa, por ejemplo, significaría que a mayor nivel educativo de la zona, menor niv el educativo de los emigrantes de las mismas, es decir, podría estar operando la "expulsión" de migrantes pobres desde zonas pudientes). Por otra parte, estos cálculos sugieren que a mayor educación, mayor ganancia para la zona de destino en el balance de educación entre los que entran y que salen; las correlaciones varían en intensidad entre ciudades, siendo más fuertes en Santiago y menos intensas en Río de Janeiro. Por cierto, aquello significa que la migración intrametropolitana tiende a agudizar la segregación residencial. De manera ilustrativa, el cuadro 7 contrasta los tres municipios de mayor y menor escolaridad en tres ciudades seleccionadas; de forma sistemática se aprecia que los municipios donde reside la elite educativa registran un balance entre educación de inmigrantes y emigrantes intrametropolitanos que le favorece ampliamente, mientras que lo contrario acontece en varias de las subdivisiones pobres.

Otro procedimiento para evaluar el impacto socioeconómico de la migración intrametropolitana es comparar la media de ingresos o de escolaridad de la población residente 5 años antes del censo, y de la población residente al momento del censo. La diferencia arroja el efecto de la migración sobre el nivel socioeconómico de la subdivisión territorial. Este efecto dependerá de la magnitud de la migración y de las diferencias de escolaridad entre migrantes intrametropolitanos y no migrantes en cada subdivisión. En general, nuevamente se aprecia que el efecto de la migración tiende a incrementar los índices socioeconómicos de las subdivisiones más acomodadas. Por ejemplo, en Río de Janeiro, Niteroi aumentó su media de ingresos (grupo 25 a 39 años) en casi un $6 \%$ por efecto de la migración, siendo sólo superado por Mangaratiba, que la incrementó en casi un $11 \%$. Estas cifras no deben interpretarse longitudinalmente, es decir, como un cambio real entre 1995 y 2000, porque el censo sólo obtiene datos de ingresos actuales, es decir al año 2000. La interpretación que cabe es que, considerando los ingresos actuales de los migrantes y no migrantes, la población actual tiene un promedio de ingresos mayor o menor que la residente en 1995.

En suma, la evidencia disponible muestra que la migración intrametropolitana tiende a aumentar la SRS, toda vez que las áreas cuyos índices socioeconómicos son altos son las que más los aumentan con la migración intrametropolitana. Por cierto, aquello no significa que la SRS esté aumentando, por varias razones. Primero, se trabajó sólo con la variable educación media; eventualmente, con otras variables socioeconómicas pudieran presentarse resultados distintos. Segundo, se consideró sólo una de las tres fuentes que determinan la cuantía y la forma de la SRS; si las otras dos apuntan en una dir ección diferente (por ejemplo, reduciendo la SRS), el balance final puede ser de atenuación y no de aumento de la SRS. Tercero, se trata de una visión temporal cuya estabilidad histórica es incier ta; ya sea por razones de mercado (precios de los suelos), de infraestructura (apertura de red vial hacia áreas de expansión metropolitana) o de valoración cultural, la migración intrametropolitana puede modificar los sesgos socioeconómicos verificados con las cifras anteriores y cambiar su efecto sobre la SRS.

\section{Sobre las consecuencias de la SRS}

La hipótesis dominante es que la SRS entraña consecuencias adversas, aunque la evidencia y los estudios empíricos sobre las mismas son más bien escasos en América Latina (Dur eau et al., 2002), aunque no inexistente (Sabatini, Cáceres y Cerda, 2001).

En Estados Unidos, la interpretación realizada respecto del efecto vecindario ha estado orientada por diferentes marcos teóricos de matriz sociológica, como: (a) las teorías del contagio o influencia del grupo de pares; (b) la teoría de la socialización colectiva a partir del modelo que entregan los adultos del barrio; y (c) la teoría institucional, que destaca el rol de las escuelas. También se han destacado canales como la dis- 
tancia física y aislamiento del núcleo urbano, la calidad de los servicios locales y la exposición a crimen y violencia. (Marpsat, 1999).

En todo caso, hay evidencia dispersa que indica que la segregación tiene efectos negativos en el capital humano, y que ejerce influencia en los riesgos de ser víctima de delitos. Con respecto al desempeño educativo, se ha visto que éste varía de acuer do a las características sociales de los barrios y ciudades, y que la descentralización y la suburbanización han creado un ambiente desfavorable para la integración escolar, de modo que el incremento de la segregación residencial ha favorecido aumentos de la segregación escolar (Wang, 2003), situación que genera barreras para el desarrollo de la resilencia y desempeño educativo de los niños de barrios que concentran poblaciones desfav orecidas, llevando a concluir que enfrentar la segregación escolar tienen importantes nexos con políticas dirigidas a aminorar la segregación residencial. Con respecto a los nexos de segregación y exposición al delito, estudios sobre ciudades de EE.UU. (citados por Borja y Castells, 1998) muestran que la concentración espacial de negros pobres favorece la criminalidad, y afecta especialmente a los grupos segregados. Según esta fuente, entre 1980 y 1992 la proporción de hogares estadounidenses que sufrió alguna forma de criminalidad se redujo más de un tercio, pero al mismo tiempo la probabilidad de los negros se ubicó nueve veces más alta que el promedio de los blancos, situación que se explica porque la segregación constituye el factor estadísticamente más explicativo de la tasa de homicidios.

En América Latina, existen estudios sobre las consecuencias sociales de la segregación. Para Montevideo, los estudios de Katzman (1999) comprobaron relaciones de la segregación (medida por el status ocupacional) con rezago o abandono del sistema educativo, frecuencia de jóvenes varones que no estudian ni buscan trabajo, y maternidad adolescente fuera del matrimonio. Es destacable que la influencia de la composición social del barrio sobre situaciones de riesgo en Montevideo persistió aun después de controlado el efecto de otras variables como el clima educacional del hogar con respecto al rezago escolar, la composición familiar respecto a la inactividad juvenil y el nivel de instrucción materna con respecto a la conducta de embarazo adolescente.

Otros estudios sobre Montevideo postulan que los barrios con tasas más altas de crecimiento poblacional son los que presentan mayores probabilidades de tasas elevadas de delincuencia (Retamoso \& Corbo, 2003).

Estudios de Sabatini, Cáceres y Cerda (2001) sobre las áreas metropolitanas de Chile, muestran que la segregación parece haber incrementado la gravedad de su efecto, lo que es visible en el incremento de las correlaciones inversas entre segregación social (medida por la ocupación del jefe de hogar) con indicadores de desintegración social (retraso escolar, desempleo juvenil y embarazo adolescente). Katzman (1999, 2001 y 2003) postula que el contexto urbano actual plantea una especial trascendencia negativa de la segregación residencial en orden a deprimir las oportunidades de movilidad social. Según este autor, en la región se halla en curso una tendencia inédita de segmentación en lo laboral, lo educativo, y además en el uso de servicios públicos y la ocupación de zonas residenciales, conformando un cuadro que amenaza con consolidar la rigidez distributiva e inmovilidad social, que ya forma uno de los flancos débiles del desarrollo latinoamericano.

Los efectos de la segregación en debilitar los activos de los hogares pobres -entre éstos el capital social- constituyen una línea de análisis importante en los últimos tiempos para la región. La segmentación urbana restringiría las redes de los pobres exclusivamente a otras personas de igual condición debilitando vínculos y puentes interclases y conformando barrios escépticos sobre la posibilidad de movilidad social vía trabajo, lo que aumentaría la probabilidad de conductas que bloquean la acumulación de capital humano y disminuyen la capacidad de generar ingr esos laborales por los jóvenes. La interacción entre segregación residencial y segmentación escolar conforma una situación especialmente delicada, por sus efectos en la diferenciación social y pérdida de posibilidades de interacción elementales para la formación de un espíritu de cuerpo social y capital social (Katzman, 2001). 


\section{Conclusiones y desafíos de política relativos a la SRS}

Este ar tículo ha buscado aportar en la medición de la SRS en los países de la región, así como profundizar en el examen de la migración intrametropolitana en tanto determinante de los procesos de estructuración de la geografía social de las ciudades, y de modo más general, discutir las consecuencias sociales de la SRS. Esta sección final se destina, en primer lugar, a destacar algunas conclusiones del análisis realizado sobre la realidad urbana latinoamericana, resaltando el carácter de problema de políticas públicas que reviste la segregación residencial en nuestra región. En segundo lugar se revisa la experiencia de algunos países en la aplicación de programas destinados a mitigar la segregación residencial o sus efectos, y se termina planteando algunas áreas de interés para una política de inclusión.

La segregación residencial en la región ha cobrado centralidad en un momento en que la concentración del ingreso, la pobreza y la fragilidad de los gobiernos y de la gobernabilidad están absolutamente vigentes. De hecho, la segregación se perfila como un mecanismo particularmente importante en la reproducción de las desigualdades socioeconómicas, el aislamiento de los pobres y la inseguridad ciudadana, especialmente para los pobres. En particular, la acumulación de capital educativo y social -este último entendido como vínculos, contactos y participación en redes- de las nuevas generaciones parece ser especialmente sensible a las modalidades de concentración territorial de la pobreza.

La aproximación empírica a la SRS en América Latina y el Caribe muestra que las áreas metropolitanas de la región son ciudades segregadas, pero que su intensidad no alcanza los niv eles de separación residencial racial que hay en las áreas metropolitanas de Estados Unidos, lo que en ningún caso es tranquilizador. En efecto, el estudio de las pautas de localización de gr upos socioeconómicos polares haciendo uso de los microdatos censales de Chile (Área Metropolitana del Gran Santiago, 1992); México, (Zona Metropolitana de la Ciudad de México, 2000) y Perú (Área Metropolitana de Lima, 1993), muestra que las elites de estos tres centros urbanos tienen un claro patrón de concentración territorial, bajo una modalidad de SRS a gran escala; esta es particularmente intensa en Santiago, donde los ámbitos ocupados por la elite son altamente homogéneos. Puede concluirse que las pautas de localización de los gr upos sociales extremos (ricos y pobres) deben ser observadas en detalle por su relevancia en la estructuración de las pautas de segregación urbana y en el tipo de políticas públicas a desarrollar para favorecer la integración.

Respecto al tipo de variables y escala geográfica que marcan más la separación de los grupos sociales, se estudiaron dos variables socioeconómicas clásicas: (a) las car encias habitacionales, que constituyen una dimensión relevante de la pobreza; y (b) la educación, atributo estrechamente vinculado con la distribución del ingreso urbano. Usando las carencias habitacionales se detecta una SRS que opera más bien a pequeña escala. Cuando la estratificación social es realizada por medio de la escolaridad del jefe de hogar ocurren dos fenómenos: se alcanzan niveles más altos de SRS a gran escala y se verifica que dentro de las subdivisiones de pequeña escala hay mayor intensidad de la conformación de zonas socialmente homogéneas. Puede concluirse que el diseño de indicadores políticos de segregación debe seguir la línea de profundización de variables relativas a educación, y que la intervención en la SRS debe realizarse con referencia a distintas escalas y modalidades de localización involucradas de los grupos sociales: la segregación a gran escala de los grupos acomodados y la conformación de bolsones de bajo capital educativo en el resto y mayoría de la ciudad.

En materia del estudio realizado sobre la migración intrametropolitana y su papel en las tendencias de la SRS, el procesamiento de datos censales de educación para cuatro aglomerados metropolitanos de América Latina muestra que existe una relevante selectividad socioeducacional "hacia arriba", entre los que se mueven dentro de la ciudad, y que las pautas recientes de movilidad intrametropolitana constituyen factores de agudización de la segregación residencial en todos los centros urbanos analizados. En suma, si bien los grandes centros urbanos todavía no alcanzan los 
grados de segregación residencial racial de Estados Unidos, igualmente muestran síntomas preocupantes de segmentación socioterritorial, y las tendencias de movilidad se perfilan como fuerzas de agravamiento de la segr egación. Por todo lo descrito, queda de manifiesto la impor tancia de elaborar una agenda coherente de políticas públicas destinada a intervenir sobre la segregación residencial en América Latina.

$\mathrm{Al}$ respecto, cabe destacar en primer lugar la jerarquía alcanzada por este asunto en las agendas políticas; tanto los planes de acción latinoamericanos como europeos han comenzado a plantearse la segregación residencial como un área de intervención. En efecto, en América Latina el Plan de Acción Regional de América Latina y el Caribe sobre Asentamientos Humanos (CEPAL, 2001), aprobado en la reunión regional de América Latina (Santiago, 1995) preparatoria de la Conferencia de Naciones Unidas sobre los Asentamientos Humanos (Habitat II, realizada en Estambul en 1996), identificó la gobernabilidad como un área estratégica del hábitat, planteando la necesidad de programas de intervención que busquen la integración espacial y social del territorio urbano. En lo referente a localización de la vivienda social se subrayó la necesidad de otorgar especial cuidado al acceso expedito al empleo y a los servicios urbanos, así como de disminuir los niveles de segregación espacial de los pobres. Asimismo, se destacó que la gobernabilidad de las ciudades se vería mejorada en tanto se eviten procesos de expulsión de población, sea fortalecida la componente de espacio público de encuentro en zonas residenciales y se desarrollen programas de prevención de problemas de inseguridad y violencia urbana, entendiendo estas últimas como vinculadas a problemas de segr egación y exclusión.

Pese a la importancia atribuida al tema de la segregación residencial en el plan de acción regional, como a lo recurrente de su mención en las declaraciones de política habitacional y urbana latinoamericanas, en nuestra región la segregación no es un campo donde exista experiencia significativa de políticas explícitas o directas destinadas a aminorarla. Hay algunos programas que pueden atenuar algunas de las adversidades que entraña la localización periférica de los pobres, sobre todo en materia de equipamiento y accesibilidad. También hay preocupación manifiesta -aunque no necesariamente traducida en medidas concretas- sobre segregación en los planes de vivienda social.

Podemos referirnos, en este sentido, a los programas focalizados territorialmente; esta es una práctica de creciente importancia, que busca mejorar la condición de barrios que concentran poblaciones pobres y que puede favorecer la localización de los pobres en zonas dotadas de infraestructura e integradas a la ciudad.

Con respecto a los planes de vivienda social masivos, éstos son crecientemente reconocidos como instrumentos que pueden conducir a la segregación. Una línea de intervención en este circuito son los subsidios especiales de renovación urbana, que buscan quebrar el sino de que la vivienda social se emplaza en la periferia, logrando la construcción de alojamientos en zonas con ventajas de infraestructura. La experiencia muestra que estas intervenciones, si bien han logrado dinamizar la actividad constructiva en zonas céntricas, no han podido favorecer la integración urbana de los pobres, sino más bien la localización de sectores medios. Otra línea relevante es la aplicación de programas de rescate de conjuntos de vivienda social deteriorados; hay experiencias en este sentido en São Paulo (www.cdhu.sp.gov.br) y en el D.F. de Ciudad de México (SEDESOL, 2003). En Chile, la Reforma Urbana propuesta por el gobierno plantea que la segregación también puede ser atacada por medio de programas de movilidad social, esto es, el fomento de mercados de transacción de viviendas usadas en barrios de vivienda social (MINVU, 2001).

La experiencia de países desarrollados entrega aprendizajes para la región. En Europa, la segregación residencial (socioeconómica, étnica y religiosa) es objeto de creciente preocupación y de intervención. La perspectiva europea de desarrollo espacial plantea explícitamente que la promoción de áreas urbanas integradas r requiere de estrategias sensibles con las necesidades de diversidad social y funcional, para lo cual se requiere abordar las distintas dimensiones de exclusión que operan territorialmente. Se percibe que la segregación de familias pobres e inmigrantes, concentrados en 
cascos antiguos y grandes conglomerados de vivienda social, generan problemas de política por su relación con desventajas económicas, desempleo y estigmatización social. El objetivo es romper los nexos de la residencia en barrios segregados y excluidos con el desempleo y la desintegración social. Para dicho propósito, el plan de acción en desarrollo urbano sustentable de la Comunidad Económica Europea (CEE) (European Comission, 2002 y 2003) establece, dentro de sus grandes áreas de política, la promoción de equidad e inclusión social y la regeneración de áreas urbanas en dificultades. Las acciones previstas para estos fines abarcan fondos focalizados territorialmente, destinados a financiar la ejecución de proyectos multisectoriales de regeneración urbana en zonas que conjugan tensiones sociales, criminalidad y declinación económica. La integración alude a objetivos orientados a mitigar el desempleo de largo plazo en poblaciones excluidas, mejorar acceso a servicios y educación, promover desarrollo económico y comercial, mejorar el medio físico, prevenir delincuencia juvenil y for talecer la comunidad.

En Suecia, los migrantes enfrentan severos problemas de integración y desempleo en la periferia de las grandes ciudades. Estas situaciones llevaron a formular programas focalizados territorialmente en barrios de tres grandes ciudades del país, destinados a mejorar las condiciones de vida de planes de vivienda social masiva; esto es, barrios que concentraban personas excluidas, alcohólicas y drogadictas (Andersson, 1998). En Inglaterra y Francia se han implementado otras políticas contra la segregación, tales como cuotas de vivienda social por áreas o distritos, mientras que en Estados Unidos se han ensayado proyectos de dispersión de familias pobres en barrios de clase media, como asimismo programas de remodelación de conjuntos de vivienda social deteriorados (Sabatini, Cáceres y Cerda, 2001). En Francia, varias generaciones de políticas emprendidas para enfrentar la segregación han consolidado el objetivo y concepto de la mixtura social hacia los años '90, desarrollándose políticas e instr umentos que buscan distribuir a los pobres a través de la ciudad, así como también recursos municipales (IAURIF, 2002).
La experiencia europea arroja varias lecciones prácticas. Con respecto a la aplicación de programas de reciclaje, se advierte que éstos no siempre logran los resultados esperados, pudiendo ocurrir que con la intención de combatir el deterioro urbano asociado a la segregación se refuerce la segmentación social del espacio urbano. En un plano positivo, los programas de mejoramiento de zonas de vivienda social pueden ser muy innovadores. De modo similar al enfoque compensatorio aplicado en políticas de desarrollo regional, estas intervenciones son destacables por seleccionar ár eas geográficas de intervención en función del concepto de distancia social. Este tipo de programas muestra, además, que problemas locales de ex clusión pueden ser abordados simultáneamente por actores locales y centrales, incluso en contextos de gestión urbana altamente descentralizada (Andersson, 1998).

De la experiencia francesa se destaca que los programas que se emprendan deben enmarcarse en estrategias globales que hagan frente a la segregación como un problema de escala urbana general, y no puntual o reducido al tema de las disparidades de calidad de vida o finanzas municipales (IAURIF, 2002).

En suma, más allá de la casuística internacional, la primera conclusión de políticas es que la SRS debe ser enfr entada mediante una perspectiva integral, con medidas tanto directas como indirectas, relativas tanto a determinantes como a efectos y mediante estrategias que vinculen las dimensiones social y urbana. Las políticas públicas inter esadas en abordar la segregación urbana deben enfocar este problema en el marco de la integración urbana y combate a la exclusión social en sus distintos niv eles y dimensiones. Políticas efectivas en este sentido serían aquellas que modifican la segregación, pero también barreras que fav orecen la exclusión. Goschel (2001) destaca correctamente que las condiciones de personas desaventajadas que viven en áreas segregadas pueden ser muy difer entes si se favorece la disolución de la segregación, pero no por ello se van a modificar otras barreras que dificultan la integración a otros niveles. Inclusive las condiciones pueden deteriorarse si se aplican políticas que promueven 
la mezcla social, sin intervenir en las restantes esferas de la integración.

Otra conclusión importante es que si bien la segregación es una materia de índole espacial, por su interacción con la cuestión social es altamente sensible a las políticas de bienestar, las que permiten controlar las expresiones espaciales de la polarización social que se transmiten a través de la segregación. Se ha planteado que regímenes de bienestar socialdemócratas comprueban que la existencia de políticas de acceso universal a servicios sociales de salud, educación y transpor te han servido para controlar los efectos negativos del crecimiento de la polarización social entre vecindarios (Katzman, 2001). Los canales mediante los cuales el Estado de Bienestar ejerce su influencia son: (a) redistribución económica (impuestos progresivos, políticas de salarios y segur os de desempleo, invalidez y vejez), esto es, mecanismos que posibilitan mejorías de la capacidad adquisitiva de sector es de menores recursos, incluida su capacidad de demanda habitacional en barrios integrados; (b) intervención del mercado de la vivienda por medio de subsidios a sectores de ingreso medio y bajo al arr endamiento y regulación de precios, sistema con similares efectos que el anterior mecanismo; y (c) sistemas de planificación postmodernos, mediante los cuales el Estado modela el paisaje físico de las ciudades y favorece mejores condiciones a la integración urbana y social del conjunto de residentes.

Con respecto al campo que plantean las políticas dirigidas a moderar los efectos de la SRS, en particular la concentración espacial de los pobres en zonas periféricas, queda de manifiesto la importancia de decididas políticas de focalización territorial tanto de inversiones del gobierno central, como de instrumentos de planeación urbana pro-integración social. Nos referimos a programas tendientes a fomentar la presencia de factores urbanos de progreso social, como son mayor mixtura de usos de suelo y consolidación de equipamiento e infraestructura. Con respecto al nuevo desarrollo inmobiliario emergente pautas de condominios cerrados y fragmentación urbana-, debiera discutirse una serie de políticas centradas en la generación de espacios públicos compartidos por distintos grupos sociales.
El aislamiento social de los pobres urbanos que resulta de la segregación residencial constituye un campo importante de intervención por medio de políticas que aminoren la segmentación espacial del mercado de trabajo y de los servicios sociales (principalmente educación), situaciones que redundan en la pérdida de espacios de encuentro informal entre personas de distinta clase social. En el plano de la política social, los barrios del tipo ghetto plantean una importante demanda de intervenciones de desarrollo comunitario que intervengan como "colchones" de planes de vivienda que originan estos asentamientos, como asimismo de políticas universales que favorezcan parámetros básicos de integración social y proyectos innovadores que atiendan las múltiples demandas de apoyo que plantea la subcultura marginal existente en estas poblaciones, y la presencia de factores de transmisión intergeneracional de la pobreza. En particular, el circuito que se establece entre segregación, adquisición de capital educativo y oportunidades de movilidad social de los niños plantea un campo de políticas centradas en la dimensión espacial de distintas variables que afectan el desempeño escolar: (a) los grupos de pares, mediante políticas de beca de niños pobres en escuelas de mejor nivel socioeconómico o desarrollo de escuelas integradas; (b) los modelos de rol, a través de políticas urbanas que posibiliten la presencia de adultos exitosos en barrios populares o políticas de desarrollo comunitario que favorezcan el liderazgo; (c) las necesidades de mejoramiento de escuelas de barrios con carencias; y en general, proyectos que atiendan la expresión espacial de la trilogía familia-barrio-escuela (Katzman, 1999, 2001 y 2003).

En materia de políticas dirigidas a prevenir la segregación o -dicho de otro modo- a favorecer patrones de crecimiento urbano socialmente sustentables, se requiere de nuevos esquemas de políticas de vivienda y desarrollo urbano que posibiliten la plena inserción urbana de los sectores modestos a través de la radicación de familias en sus comunas de origen, pudiendo plantearse la necesidad de explorar mecanismos que se traduzcan en: (a) gravámenes a zonas y proyectos que contribuyen a la expulsión de hogares pobres, cuyo destino sean fondos de compensación para mejoramiento de barrios pobres; $y$ (b) incentivos a pro- 
yectos que contribuyan a la integración urbana de sectores de menores recursos, sea por la localización o la valorización de su activo habitacional. También parecen requeridas medidas preventivas de futuros procesos de desalojo (gentrificación) de zonas que han sido consolidadas en lo urbano, y que debieran seguir siendo espacios de acogida para la demanda de alojamiento de los sectores de menor es recursos.

El manejo del espacio público constituye un factor de integración urbana que debiera estar al centro de políticas de mitigación de la segregación. Katzman (2001) destaca que las clases medias han desertado de los lugares y servicios frecuentados por sectores de menor es recursos, mostrando la necesidad de intervenir la segmentación de servicios sociales básicos en zonas pobres. Surge con gran importancia el espacio público como elemento ordenador de la ciudad y como factor de redistribución e integración social, corrigiendo enfoques limitados de construcción de ciudad por medio sólo de vivienda más vialidad. En lo espacial, la segregación plantea, entre sus múltiples expresiones, una necesidad de creación de centralidades en barrios pobres o aislados por medio de intervenciones en el espacio público, y la relación de éste con el ejercicio ciudadano (Borja, 1998).

Por último, no debe perderse de vista que la segregación se muestra esencialmente como un problema que afecta más intensamente al fenómeno metropolitano, lo que supone la necesidad que dicha instancia de gobierno metropolitano se plantee objetivos al respecto.

\section{Referencias bibliográficas}

Andersson, R. (1998). Segregation dynamics and urban policy issues in Sweden. International Conference on Divided Cities and Strategies for Unidivided Cities, Goteborg, Sweden. www.international.metropolis.net/event/goth/ segregation.html

Anselin, L. (1995). "Local Indicators of spatial association-LISA". Geographical Analysis, 27.

Aroca, P. (2000). Econometría espacial: una herramienta para el análisis de la economía regional. Documento presentado al V Encuentro de la
Red de Economía Social, Panamá, 5-7 de septiembre de 2000. http//:decon.edu.uy/ network/pdfs/aroca.pdf

Arriagada, C. \& D. Simioni (2001). Dinámica de valorización del suelo en el área metropolitana del Gran Santiago y desafios del financiamiento urbano. Santiago: CEPAL, LC/L.1646-P.

Borja, J. (1998). "Ciudadanía y espacio público”. CLAD Reforma y Democracia, 12.

Borja, J. \& M. Castells (1998). Local y global: la gestión de las ciudades en la era de la información. Madrid: Taur us.

Castells, M. (1997). La era de la información: economía, sociedad y cultura, Madrid, Alianza Editorial.

CEPAL (2001) Plan de Acción Regional de América Latina y el Caribe sobre asentamientos humanos: versión actualizada. Santiago: LC/ G.2143.

CEPAL/CELADE (2002). Vulnerabilidad sociodemográfica: viejos y nuevos riesgos para comunidades, hoganes y personas. Sintesis y conclusiones. Santiago, LC/G.2170(SES.29/16).

CEPAL/HABITAT (2001), El espacio regional: hacia la consolidación de los asentamientos humanos en América Latina y el Caribe. Santiago: CEPAL, LC/G.2116/Rev.1-P.

Dureau, F. et al. (coords.) (2002). Metrópolis en movimiento. Una comparación internacional. Bogotá: IRD, Alfaomega.

Easterly, W. \& R. Levine (2001). "It's not factor acumulation: stylized fact and growth models". The World Bank Economic Review, 15, 2.

European Comission (2002). European spatial development perspective (ESDP). Regional Policy-Infor egio. www.europa.eu.int

European Comission (2003). Sustanaible urban development in the European Union: a framework for action. www.europa.eu.int

Goschel, A. (2001). "Integration and The City". German Journal of Urban Studies, 40, 1. www.difu.eu/publikationen/dfk

IAURIF (2002) Mixite sociale et segregation: les realités d' hier et d' aujourdhui et les actions publiques. Institute D' Amenagement et D' Urbanisme de la Region de Ile de France. www.iauriforg

Jargowsky, P. (1996). "Take the money and run: economic segregation in U.S. metropolitan areas". American Sociological Review, 61, 6. 
Katzman, R. (ed.) (1999). Activos y estructuras de oportunidades. Estudios sobre las raices de la vulnerabilidad social en el Uruguay. Montevideo: PNUD/CEPAL, LC/MVD/R.180.

(2001). "Seducidos y abandonados: el aislamiento social de los pobres urbanos", Revista de la CEPAL, 75.

(2003). La dimensión espacial en las politicas de superación de la pobreza urbana. Documento presentado a la Reunión de Expertos en Pobreza Urbana, División de Medio Ambiente y Asentamientos Humanos, Comisión Económica para América Latina y el Caribe (CEPAL), Santiago de Chile, 27-28 de enero.

Kaztman, R. \& G. Wormald (eds.) (2002). Trabajo y ciudadanía. Los cambiantes rostros de la integración y exclusión social en cuatro áreas metropolitanas de América Latina. Montevideo: Sofilco.

Lungo, M. \& S. Baires (2001). Socio-spatial segregation and urban land regulation in Latin American cities. Documento presentado al International Seminar on Segregation in the City, Lincoln Institute of Land Policy, Cambridge (Mass.), julio.

Marpsat, M. (1999). "La modélisation des 'effets de quartier' aux États-Unis”. Population, 54, 2.

Massey, D. (2002). "A brief history of human society: the origin and role of emotion in social life". American Sociological Review, 67, 1.

Massey, D., M. White y V. Phua (1996). "The dimensions of segregation revisited". Sociological Methods \& Research, 24, 2.

MINVU (2001). Reforma de la Ciudad. Documento No 1. www.minvu.cl

Redak, V. (2002). Urban policy in Europe: an assesment of EU Funding for Disadvantaged Areas: the case of Viena, Austria. International Conference of Europeanists, Chicago.

Retamoso, A. \& G. Corbo (2003). La evolución del sistema urbano uruguayo: una aproximación al fenómeno de la delincuencia y criminalidad en Montevideo. Working Papper, The Center for Migration and Development, Princeton University.

Rodríguez, J. (2001). "Segregación residencial socioeconómica: ¿qué es?, ¿cómo se mide?, ¿qué está pasando?, ¿importa?” Serie Población y Desarrollo, 16, LC/L.1576-P.

(2002). "Distribución espacial de la población de América Latina y el Caribe: tendencias, interpretaciones y desafíos para las políticas públicas". Serie Población y Desarrollo, 32, LC/L.1831-P.

Sabatini, F. (1999). Tendencias de la segregación residencial urbana en Latinoamérica: reflexiones a partir del caso de Santiago de Chile. Ponencia presentada al seminario Latin America: Democracy, Markets and Equity at the Threshold of New Millenium, Universidad de Uppsala, Suecia.

Sabatini, F., G. Cáceres y J. Cerda (2001). "Segregación residencial en las principales ciudades chilenas: Tendencias de las tres últimas décadas y posibles cursos de acción". EURE, $27,82$.

San-II Lee (2001). "Dev eloping a bivariate spatial association measure: an integration of Pearson's $r$ and Moran's I'. Journal of Geographical Systems, 3 .

SEDESOL (2003). "Programa sectorial de vivienda 2001-2006". www.sedesol.gob.mx

Sperberg, J. \& B. Happe (2000). "Violencia y delincuencia en barrios pobres de Santiago de Chile y Río de Janeiro". Nueva sociedad, 169.

Tironi, M. (2003). Nueva pobreza urbana. Santiago: Universidad de Chile, Facultad de Ciencias Sociales/RIL Editores.

Villa, M. (1991). Introducción al análisis de la migración: apuntes de clase y notas preliminares. Santiago: CELADE, Serie B, 91.

Wang, M. (2003). "Bridging the gap in urban schools: reducing educational segregation and advancing resilience promoting strategies". www.temple.edu

Welti, C. (1997 y 1998). Demografía I y II. México: Programa Latinoamericano de Actividades en Población Demografía.

Wessel, T. (2000). "Social polarization and economic segregation in Welfare State: the case of Oslo". Urban Studies, 37, 11.

White, M. (1983). "The measurement of spatial segregation". American Journal of Sociology, 88, 5.

Wilson, J. (1987). The truly disadvantaged. Chicago: University of Chicago Press. 